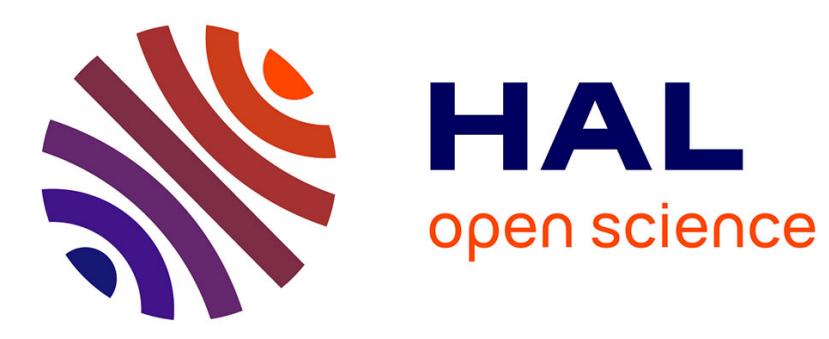

\title{
Multiple equilibria in a firing game with impartial justice
}

Damien Besancenot, Radu Vranceanu

\section{To cite this version:}

Damien Besancenot, Radu Vranceanu. Multiple equilibria in a firing game with impartial justice. 2008. halshs-00203176

\section{HAL Id: halshs-00203176 \\ https://shs.hal.science/halshs-00203176}

Preprint submitted on 9 Jan 2008

HAL is a multi-disciplinary open access archive for the deposit and dissemination of scientific research documents, whether they are published or not. The documents may come from teaching and research institutions in France or abroad, or from public or private research centers.
L'archive ouverte pluridisciplinaire HAL, est destinée au dépôt et à la diffusion de documents scientifiques de niveau recherche, publiés ou non, émanant des établissements d'enseignement et de recherche français ou étrangers, des laboratoires publics ou privés. 
October 24,2007

\title{
MULTIPLE EQUILIBRIA IN A FIRING GAME
}

\section{WITH IMPARTIAL JUSTICE}

\author{
Damien Besancenot* and Radu Vranceanu ${ }^{\dagger}$
}

\begin{abstract}
In many European countries, a majority of employees are hired under very protective labor contracts that restrict the ability of the employer to dismiss them. In particular, employees can take to courts the firm's layoff motive. Given the high costs specific to so-called economic motives and judges' limited ability to process an ever growing flow of cases, in the last few years firms have been tempted to invoke faked personal motives for firing "good" workers. This paper shows that the interaction between firms, employees and the labor judicial system is consistent with multiple equilibria. Hence firing costs depend not only on variables under the control of the government, but also on the nature of the equilibrium. Policies aiming at increasing flexibility, interpreted as a reduction in firing costs, should consider the possibility of shifting from a high to a low firing costs equilibrium.
\end{abstract}

Keywords: EPL, Labor judges, Firing costs, Layoff motive, Multiple equilibria.

JEL Classification Index: K31, J32, J53.

Document de travail CEPN 2008-01

*University Paris 13. E-mail: besancenot@univ-paris13.fr

†ESSEC Business School, PB 50105, 95021 Cergy, France. E-mail: vranceanu@essec.fr 


\section{Introduction}

Building on the basic principle according to which labour market institutions have a substantial impact on the labor market performance (Blanchard and Wolfers, 2000; Phelps and Zoega, 2001), in the recent years economists begin to pay special attention to the relationship between job creation and the strictness of employment protection legislation (EPL). EPL can be defined as the set of rules that govern the hiring and firing of employees, rules which include regulation on temporary contracts, specific requirements for collective dismissal and protection of regular workers against individual dismissal (OECD, 2006; Cahuc and Koeniger, 2007).

In all the industrialized world the law protects employees against discriminatory behavior on behalf of the employer (because of gender, age, race and so on). Yet many South European countries took workers' rights one step further and ruled that fired workers can take the employer's decision to courts even if the motive of the dismissal involves no discriminatory practice. In general, a firm can decide to separate from an employee if at one moment in time the optimal organization of the production process requires less labor, or because the worker does not fulfill his tasks in an adequate manner. The former set gathers what we call "economic or objective" motives and the latter contains "personal or subjective" motives. Depending on the country, when the firm opts for the "economic" motive, it must pay the worker a severance payment, which, in general, is quite substantial. ${ }^{1}$ When the worker's behavior on the workplace is at stake, the personal motive may be invoked and the firm can fire the worker by paying him a small compensation; no compensation is due if the worker made a serious professional fault. Hence judges - specialized in labor cases or civil law - have legal competence in deciding whether the motive of a dismissal is "valid" or "just". In some countries only personal motives can be investigated while in other countries economic motives can also be taken to courts. Judges can impose substantial fines on the firm found guilty of abusive dismissal.

While in the past strict employment protection legislation against economic dismissal was seen by the most voluntarist European governments as a way to deliver high job security, over time it

\footnotetext{
1 For instance, in Spain the dismissal severance amounts to 33 (45 for older contracts) days of salary per year of employment. Large severance payments apply to Portugal, Italy and Germany for large firms. In France the official severance payment is relatively lower, but the legally accepted motives fall in a very narrow range.
} 
turned out that strict EPL not only reduces the number of dismissals, but also adversely affects the entry rate from unemployment into work. As a consequence, strict EPL appears to be a quite ineffective mean to contain high unemployment. ${ }^{2} \quad$ The going position of the European Commission is to support "flexicurity", a catch-all concept for joint actions towards loosening EPL and strengthening the support provided to the unemployed, both in terms of income and facilities to find a job and get trained (European Commission, 2006, 2007).

This paper aims at providing an introspection into the nature of these legal firing costs within the institutional setup specific to South European countries. Its original contribution to existing EPL literature is to show that their existing labor - justice interaction is consistent with multiple equilibria. It turns out that firing costs depend not only on control variables that can be decided by the government, but also on the prevailing equilibrium. Hence, policies aiming at improving the employment performance of a given economy should pay due consideration not only to the impact of small variations in firing costs, but also to the possibility to shift from one equilibrium to another.

The model builds on an analysis of the French labor market. In this country, $90 \%$ of the employed persons are hired under a well-defined "open-ended labor contract". ${ }^{3}$ In general, the firm that fires a worker hired under a such an open-ended contract must pay a severance indemnity, depending on the motive of the dismissal. The French law distinguishes between economic motives, where separation occurs basically because the firm strives to maintain its competitive edge and personal motives, because the worker's capabilities or behavior no longer match the firm's needs; one particular personal motive is the "serious professional misdemeanor", where the worker commits a serious abuse (in this case, he gets no severance payment). Notice that the law provides no formal definition for the personal motive (the law only states that the cause must be "real and serious"), and what can be accepted or not as a valid motive emerged from judicial practice over time (Blanchard and Tirole, 2004; Pigoni and Zuary, 2003; Cahuc and Kramarz, 2004). Economic

\footnotetext{
2 See OECD (2006) or the June special issue of the Economic Journal (Cahuc and Koeniger, 2007) for a review of recent empirical findings. See Ljungqvist (2002) of Cahuc and Zylberberg (2004) for a survey of the main models, including pionnering work by Bentolila and Bertola (1990) and Bertola (1990).

3 The other $10 \%$ are hired under various forms of temporary contracts that imply a much lighter EPL.
} 
motives are defined in more specific terms, which all may be related one way or another to the firm's financial solvency. When the employer fires a worker for personal motives it must pay him a relatively small severance payment, between $1 / 10$ th to $1 / 6$ th of the monthly wage per year of experience; it must pay him twice as much if the economic motive is invoked. Yet, if the fired employee takes the decision to a court the labour judge can rule that the motive is not valid; in this case, he can ask the firm to pay to the worker a large indemnity (for unfair dismissal) of at least six months of salary. In some cases, the judge can even ask the firm to reintegrate the employee; the firm must then pay the fine and the wage over the whole not worked period. Over time, it became more and more difficult to fire someone for economic motives, not least because courts tend to give a very narrow interpretation of the valid motives (Blanchard and Tirole, 2004). Unsurprisingly, the number of layoffs for personal motives increased by $40 \%$ between 2001 and 2003 (Lagrenne and Leroux, 2006). Cahuc and Kramarz (2004) surmise that firms probably tend to invoke faked personal motives, while the true motive is economic. In 2004, $26 \%$ of the workers fired for a personal motive went to courts (in general, they dispute the motive of the dismissal). In $64.5 \%$ of the cases, the outcome of the trial was favorable to the employees (Munoz-Perez and Severin, 2005).

We takes stock on this set of rules and institutions to build a game between firms - that must reduce their staff, workers - who can sue their former employers, and judges - who must shed light on the case. At the outset of the game, the firm must decide on the optimal layoff policy. If the firm decides to fire a worker for "economic motives", it must pay him a substantial compensation, whose amount is exogenously given. In this case, the worker takes the money and agrees to leave without taking to courts the firm's decision. If the firm wants to spare this cost, it may invoke a "personal motive" where the decision to fire the worker puts forward his inadequacy with the job. In this case, we assume that the firm pays him nothing (actually, it may pay him a small benefit). While for some workers such a claim is sensible since they do not behave well, for the majority of workers such a motive is clearly an abuse. Why the firm should take the risk to follow this policy? Because judges, as any human being, can make errors. In particular, the more files a judge must process, the larger should be the risk of taking a wrong decision. We show that this 
simple but plausible set-up is consistent with multiple equilibria that can be ranked according to a social welfare criterion. If firms fire for personal motives only those workers who really qualify for such decision, these workers have little incentive to take to courts the decision given that judges, who have little cases to analyze, can shed full light on the file. But if firms fire all workers for personal motives, their strategy may be optimal too, since judges must process too many files and, with an equilibrium probability, may sit with the firm even if the latter had committed an abuse. In between these polar cases, some "hybrid" equilibria can be unveiled, where players play mixed strategies. In the pooling and hybrid equilibria there are good workers fired for personal motives and who get no decent compensation; the judicial system is crowded with files and overworked judges take the wrong decision with a positive probability. In particular, when in the hybrid equilibrium good employees are unduly fired for personal motives, the judges' error margin edges up, which in turn validates the "unfitted" workers's decision to go to courts. But because these unfitted workers go to courts, firms can be tempted to fire a good worker for a personal motive.

To our knowledge, the only paper that investigates the complex relationship between firms' firing strategies and the judicial system was worked out by Ichino, Polo and Rettore (2003) who take stock of the Italian experience. ${ }^{4}$ For so-doing, they model the judge's behavior, who must decide on whether a given misconduct is sufficient for firing someone. They sit with the worker if his misconduct is milder then the "representative" misconduct, and vice versa. In turn the representative misconduct depends on the average misconduct of all fired persons. When many workers are fired, the average misconduct is softer, so judges tend to sit with workers more often. Hence firing costs appear to be counter-cyclical. In the paper at hand we do not provide an explicit model of the judges' decision making process. We only take a shortcut and posit that in a situation of imperfect information about the true type of the worker, the probability that the judge gives a verdict favorable to the worker should match the frequency of good workers in total population of suing workers. Clearly, any more sophisticated model should fulfill this criterion, if else justice is biased in favor of workers or firms.

\footnotetext{
${ }^{4}$ Following the pionnering work of Posner (1993), there were several empirical attempts to estimate variables that have a bearing on the quality of a judge decision. Most of this studies point out that workload is an important factor (Taha, 2004). A theoretical model describing the judge's behavior in a genuine judicial framework with imperfect information and given judges' career concerns, was worked out by Levy (2005).
} 
The paper is organized as following. The next section introduces the main assumptions and strategies. Section 4 puts forward the equilibria of the game, starting with pure strategy equilibria and continuing with mixed strategy ones. The last section presents our conclusions.

\section{The model}

\subsection{Main assumptions}

The productive sector is represented by a single firm that must dismiss a unit mass of workers. There are two types of workers, the $b$-type worker (for "bad"), who behaves "improperly" and the $g$-type worker (for "good"), who "behaves well". ${ }^{5}$ From a legal point of view, the former can be fired for a "personal motive", while the latter can be fired only for an "economic motive". Denoting by $i$ the worker's type, we have $i \in\{b, g\}$. The frequency of $g$-type workers in the total population of persons to be fired is denoted by $\alpha$, with $\alpha<1$.

When the firm fires a worker for an "economic motives" it must pay him the compensation $N$. In this case the worker takes the money and leaves the firm without opposing the firm's decision. When the firm fires the worker for a personal motive, it pays him nothing. If the firm fires a $g$-type worker for a personal motive, it clearly commits an abuse, given that, in the eyes of the law, this type of worker would qualify for the economic motive.

All workers dismissed for personal motives can take to courts the manager's decision. Going to courts involve a trial sunk cost $k$, that will be charged to the part found guilty. If a worker gets a favorable verdict, the firm must pay him a fine $y$. If the verdict is favorable to the firm, the worker has no other penalty than the trial cost $k$.

To simplify mathematical expressions, we also assume that the compensation paid when firing a worker for economic motives can be written as a multiple of the justice costs: $N=n k$, with $n>1$. We must also have $N<y+k$, if else the firm would never fire someone for an economic motive and the problem would become trivial.

The model can be cast as a sequential game featuring three rational players: the firm's manager - who decides how to dismiss a worker, the worker - who can sue the firm, the and the judge -

\footnotetext{
5 "Good" and "bad" are standard names in game theory. Here they are defined in a strict judicial perspective with no other value assessment.
} 
who rules whether the firm or the worker is right. The typical sequence of decisions goes like this (Figure 1 presents the decision tree):

At time $t=0$, Nature chooses the type $i$ of the worker who is to be fired.

At time $t=1$, the firm's manager, who knows the type of the worker, can fire him for a personal motive without compensation (action $F$ ) or can fire him for an economic motive (action $\bar{F})$; in this later case it must pay him a compensation $N$; the worker takes the money and leaves without protest: the game is over.

At time $t=2$, a worker fired for a personal motive decides whether to sue the firm for abusive dismissal (action $S$ ) or not (action $\bar{S}$ ). If he does not sue the firm, the game is over. If else, the case is taken before the judge.

At time $t=3$, the judge can either provide the high effort needed to shed light on this case (action $C$, for control) or not (action $\bar{C}$ ). If the judge plays $C$, he can unambiguously determine the true type of the worker: the game is over.

At time $t=4$, the judge who has previously followed $\bar{C}$ (did not provide the high effort), will rule that the worker's claim is right (play action $I$ ) with probability $\operatorname{Pr}[I \mid S, \bar{C}]$ or wrong with probability $1-\operatorname{Pr}[I \mid S, \bar{C}]$. (These probabilities are endogenous). The game is over.

We can introduce now the players' strategies.

\section{$2.2 \quad$ Players' strategies}

As shown in Figure 1, firm's managers and workers can take an action from their feasible set, $\{F, \bar{F}\}$ and respectively $\{S, \bar{S}\}$.

a) The strategy of the firm's manager (called player $f$ ) can be written as a function of the worker's type:

$$
s^{f}(i)= \begin{cases}\lambda F+(1-\lambda) \bar{F} & \text { if } i=b \\ l F+(1-l) \bar{F} & \text { if } i=g\end{cases}
$$

where $\lambda \in[0,1]$ and $l \in[0,1]$ are the worker specific probabilities that the firm plays action $F$ (fire the worker for a personal motive). 


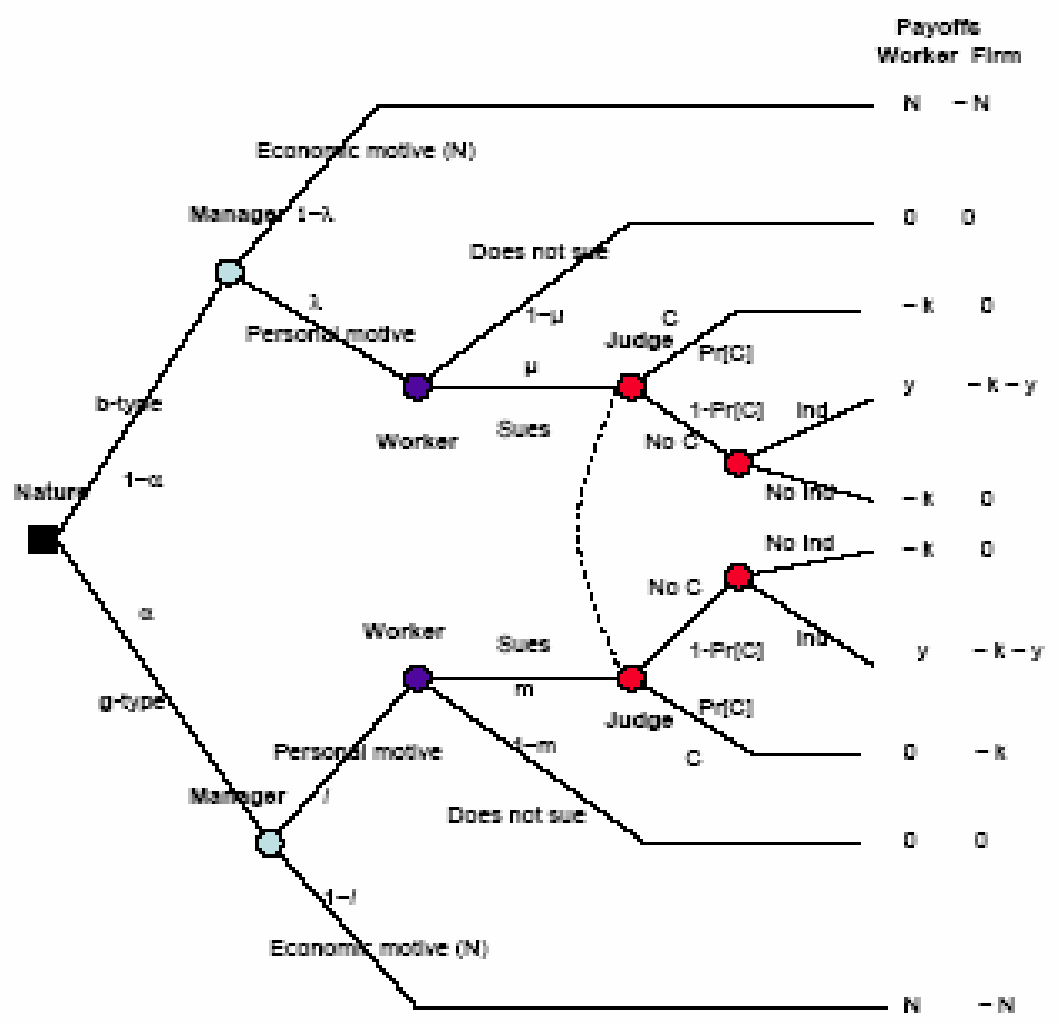

Figure 1: Decision Tree

b) The strategy of a fired worker (player $w$ ) is:

$$
s^{w}(i)=\left\{\begin{array}{cc}
\mu S+(1-\mu) \bar{S} & \text { if } i=b \\
m S+(1-m) \bar{S} & \text { if } i=g
\end{array}\right.
$$

where $\mu \in[0,1]$ and $m \in[0,1]$ are the worker specific probabilities to play action $S$ (sue the firm).

c) It is beyond the scope of this paper to provide an in-depth model of the judge's behavior, which is probably influenced by many subjective and objective factors. In order to represent the judicial process in the most simple way, we assume that the representative judge who benefits of a supportive environment can investigate cases carefully and can determine the type of the worker with unitary probability; he plays action $C$ (for control). The environment includes all that help the judge to take a good decision, such as time to study a file, the number and quality of auxiliary staff, access to data, special training, and so on. The judge who does not dispose of a supportive environment is in a situation of imperfect information and cannot implement systematically the 
control strategy: he thus plays action "control" with a probability $\operatorname{Pr}[C]$ and action "no control" $(\bar{C})$ with probability $1-\operatorname{Pr}[C]$. Hence, denoting by $P[S]$ the overall number of cases a judge must analyze every period and by $\theta$ the number of cases a judge can analyze every period (this parameter can be interpreted as a proxy for the technical efficiency of the judicial system), the probability that the judge will analyze a given case is:

$$
\operatorname{Pr}[C]=\min \left\{\frac{\theta}{P[S]}, 1\right\}, \text { with } P[S]=\alpha \ln +(1-\alpha) \lambda \mu .
$$

The model presented in this paper makes sense if the parameter $\theta$ is rather small: this means that when they are subject to a large number of cases of brought by unknown types of workers, judges get overloaded, i.e. $\operatorname{Pr}[C]<1$. In the following we will develop our arguments for the non trivial case where $\theta$ is positive but close to zero (with $\theta=0$ being a special case). If $\theta$ is large enough, there is no incentive for firms to fire for personal motives any good worker, since judges can detect the abuse without error.

In this framework, the judge's rationality can be introduced in the most straightforward way by stating that the frequency of decisions favorable to workers should match the frequency of $g$-type workers in the total population of dismissed workers who sue their firm. Indeed, any gap between the two measures would involve a systematic bias in favour of either workers or firms, which is not consistent with the principle of an impartial justice. (Any more complex model of the judge's behavior should respect this principle).

Formally, we denoted by $\operatorname{Pr}[I \mid S, \bar{C}]$ the probability that in the situation of imperfect information the judge will give a verdict favorable to the worker. Let $\operatorname{Pr}[g \mid F, S, \bar{C}]$ be the number of good workers that sue relative to the total number of suing workers, more precisely:

$$
\operatorname{Pr}[g \mid F, S, \bar{C}]=\frac{\alpha \operatorname{lm}(1-\operatorname{Pr}[C])}{[\alpha l m+(1-\alpha) \lambda \mu](1-\operatorname{Pr}[C])}=\frac{\alpha l m}{\alpha l m+(1-\alpha) \lambda \mu} .
$$

The "judge's rationality condition" (JRC) can be stated as:

$$
\operatorname{Pr}[I \mid S, \bar{C}]=\operatorname{Pr}[g \mid F, S, \bar{C}]
$$

In this setup, a good worker that sues the firm when the majority of workers who sue are of the bad type has little chance to win, and a bad worker who sues the firm when the majority of cases 
is brought by good workers, has good chances to win.

Finally, the judge's strategy can be written in a compact way as:

$$
s^{j}=\left\{\begin{array}{l}
\text { plays } C, \text { with } \operatorname{Pr}[C] \\
\text { plays } \bar{C}, \text { with } 1-\operatorname{Pr}[C], \text { then }\left\{\begin{array}{l}
\text { sit with the worker, with } \operatorname{Pr}[I \mid S, \bar{C}] \\
\text { sit with the firm, with } 1-\operatorname{Pr}[I \mid S, \bar{C}]
\end{array}\right.
\end{array}\right.
$$

Given the judge's strategy and a worker's type, workers' probability to win the case and get the compensation $y$ is:

$$
\begin{aligned}
& \operatorname{Pr}[I \mid S, g]=\operatorname{Pr}[C]+(1-\operatorname{Pr}[C]) \operatorname{Pr}[I \mid S, \bar{C}], \text { for the } g \text {-type worker } \\
& \operatorname{Pr}[I \mid S, b]=(1-\operatorname{Pr}[C]) \operatorname{Pr}[I \mid S, \bar{C}], \text { for the } b \text {-type worker. }
\end{aligned}
$$

A quick eye to these formula point to a sensible consequence of our rationality assumption: the ex ante probability that a good worker wins the case is bigger than the ex ante probability to win for a bad worker.

\subsection{Optimal strategies}

\subsubsection{The worker}

The expected payoff of a fired $b$-type worker who sues is:

$$
\begin{aligned}
E\left[U^{w} \mid S, F, b\right] & =\operatorname{Pr}[C](-k)+(1-\operatorname{Pr}[C])\{\operatorname{Pr}[I \mid S, \bar{C}] y+(1-\operatorname{Pr}[I \mid S, \bar{C}])(-k)\} \\
& =(-k)\{\operatorname{Pr}[C]+(1-\operatorname{Pr}[C])(1-\operatorname{Pr}[I \mid S, \bar{C}])\}+(1-\operatorname{Pr}[C]) \operatorname{Pr}[I \mid S, \bar{C}] y
\end{aligned}
$$

Thus, the $b$-worker sues (plays $S$ ) if:

$$
E\left[U^{w} \mid S, F, b\right]>0 \Leftrightarrow y>k X_{1}
$$

with

$$
X_{1} \equiv \frac{\operatorname{Pr}[C]+(1-\operatorname{Pr}[C])(1-\operatorname{Pr}[I \mid S, \bar{C}])}{(1-\operatorname{Pr}[C]) \operatorname{Pr}[I \mid S, \bar{C}]} .
$$

The expected payoff of a fired $g$-type worker who sues is:

$$
\begin{aligned}
E\left[U^{w} \mid S, F, g\right] & =\operatorname{Pr}[C](y)+(1-\operatorname{Pr}[C])\{(1-\operatorname{Pr}[I \mid S, \bar{C}])(-k)+\operatorname{Pr}[I \mid S, \bar{C}] y\} \\
& =y\{\operatorname{Pr}[C]+(1-\operatorname{Pr}[C]) \operatorname{Pr}[I \mid S, \bar{C}]\}+(-k)(1-\operatorname{Pr}[C])(1-\operatorname{Pr}[I \mid S, \bar{C}])
\end{aligned}
$$


Thus, the $g$-worker goes to court (plays $S$ ) if:

$$
E\left[U^{w} \mid S, F, g\right]>0 \Leftrightarrow y>k X_{2}
$$

with :

$$
X_{2} \equiv \frac{(1-\operatorname{Pr}[C])(1-\operatorname{Pr}[I \mid S, \bar{C}])}{\operatorname{Pr}[C]+(1-\operatorname{Pr}[C]) \operatorname{Pr}[I \mid S, \bar{C}]}
$$

We can easily check that $X_{1}>X_{2}$. Therefore, according to $y$, either all workers sue, or all workers do not sue, or the good workers sue while the bad ones do not. The case where the $b$-type workers sue and the $g$-type workers do not can never happen.

\subsubsection{The firm}

The expected payoff of the firm when it fires a $b$-type worker for personal motives $(F)$ is:

$$
\begin{aligned}
E\left[U^{f} \mid F, b\right] & =\mu\{[\operatorname{Pr}[C]+(1-\operatorname{Pr}[C])(1-\operatorname{Pr}[I \mid S, \bar{C}])] 0+(-y-k)(1-\operatorname{Pr}[C]) \operatorname{Pr}[I \mid S, \bar{C}]\} \\
& =\mu(-y-k)(1-\operatorname{Pr}[C]) \operatorname{Pr}[I \mid S, \bar{C}]
\end{aligned}
$$

The expected payoff of the firm that fires the $b$-type worker for economic motives $(\bar{F})$ is:

$$
E\left[U^{f} \mid \bar{F}, b\right]=-n k
$$

Hence, the firm's optimal strategy is to fire the $b$-type worker for personal motives if:

$$
E\left[U^{f} \mid F, b\right]>E\left[U^{f} \mid \bar{F}, b\right] \Leftrightarrow y<k Y_{1}
$$

with:

$$
Y_{1} \equiv \frac{n-\mu(1-\operatorname{Pr}[C]) \operatorname{Pr}[I \mid S, \bar{C}])}{\mu(1-\operatorname{Pr}[C]) \operatorname{Pr}[I \mid S, \bar{C}]}
$$

The expected payoff of the firm that fires a $g$-type worker for personal motives $(F)$ is:

$$
E\left[U^{f} \mid F, g\right]=-(y+k) m\{\operatorname{Pr}[C]+(1-\operatorname{Pr}[C]) \operatorname{Pr}[I \mid S, \bar{C}]\}
$$

and the expected payoff of the firm that fires the $g$-type worker for economic motives $(\bar{F})$ is:

$$
E\left[U^{f} \mid \bar{F}, g\right]=-n k
$$

The optimal strategy is to fire a $g$-type worker if:

$$
E\left[U^{f} \mid F, g\right]>E\left[U^{f} \mid \bar{F}, g\right] \Leftrightarrow y<k Y_{2}
$$


with

$$
Y_{2} \equiv \frac{n-m\{\operatorname{Pr}[C]+(1-\operatorname{Pr}[C]) \operatorname{Pr}[I \mid S, \bar{C}]\}}{m\{\operatorname{Pr}[C]+(1-\operatorname{Pr}[C]) \operatorname{Pr}[I \mid S, \bar{C}]\}}
$$

We can check firstly that $Y_{1}>Y_{2}$ if $(m-\mu) \geq 0$. Indeed,

$$
\begin{aligned}
& Y_{1}=\frac{n-\mu(1-\operatorname{Pr}[C]) \operatorname{Pr}[I \mid S, \bar{C}])}{\mu(1-\operatorname{Pr}[C]) \operatorname{Pr}[I \mid S, \bar{C}]}>\frac{n-m\{\operatorname{Pr}[C]+(1-\operatorname{Pr}[C]) \operatorname{Pr}[I \mid S, \bar{C}]\}}{m\{\operatorname{Pr}[C]+(1-\operatorname{Pr}[C]) \operatorname{Pr}[I \mid S, \bar{C}]\}}=Y_{2} \\
& \Leftrightarrow m \operatorname{Pr}[C]+(m-\mu)(1-\operatorname{Pr}[C]) \operatorname{Pr}[I \mid S, \bar{C}]>0 .
\end{aligned}
$$

But $(m-\mu) \geq 0$ for $X_{1}>X_{2}$ such as it has been shown before. For $X_{1}>X_{2}$ either $m=1$ and $\mu \in[0,1]$, or $m \in[0,1]$ and $\mu=0$. It turns out that $Y_{1}>Y_{2}$.

\section{Equilibria of the game}

We can study now the Nash equilibria of the game. A Nash equilibrium is defined here as a situation where workers and firms follow their optimal strategy while they expect that the other player carries out his own optimal strategy; furthermore, the judge's behavior is impartial. The equilibrium can therefore be represented by the vector of optimal strategies, $\left[l^{*}, \lambda^{*}, m^{*}, \mu^{*}\right]$.

At this point of our demonstration we cannot order $Y_{2}$ and $Y_{1}$ with respect to $X_{1}$ and $X_{2}$ (recall that these are endogenous variables). We should distinguish between two significant situations, $Y_{2}<X_{1}$ or $Y_{2} \geq X_{1}$. We study first the case $Y_{2}<X_{2}$.

\subsection{The case $Y_{2}<X_{2}$ : a separating equilibrium}

A separating equilibrium is a situation where the firm's strategy is specific to the type of worker, and workers have specific judicial strategies. Hence, judges can infer the type of the worker from his decision to sue or not the firm, that is, they can make a decision as if they were in a situation of perfect information.

It is easy to see that a possible separating equilibrium occurs if all $b$-type workers and only them are fired for personal motives and they do not sue the firm. Since judges have almost no case to analyze, they can detect the type of worker without error if one case arrives on their desk. In this context, a $b$-type worker has no individual incentive to sue. Moreover, the firm will never fire a $g$ - worker for a personal motive, if else the person will sue and win the large indemnity $y$. Hence 
the firm prefers the economic motive, which costs it "only" $N$. By eliminating all the other logical occurrences, Appendix 1 shows that this is the only equilibrium possible in the case $Y_{2}<X_{2}$. We show now formally that this equilibrium exists whatever the value of the parameters.

The two conditions of existence of this equilibrium are:

Condition (a): $k Y_{2}<y<k Y_{1}$ : all $b$-type workers and only them are fired for personal motives Condition (b): $k X_{2}<y<k X_{1}: b$-type workers fired for personal motives do not sue the firm. (If a $g$-type worker is fired for personal motives, he would sue the firm.)

In this equilibrium, we have $\lambda=1$ and $l=0$. The manager's strategy becomes:

$$
s^{f}(i)=\left\{\begin{array}{ll}
F & \text { if } i=b \\
\bar{F} & \text { if } i=g
\end{array} .\right.
$$

Let us study first condition (b). We show that the case where some $b$-type workers fired for personal motives sue the firm $(\mu>0)$ is impossible. Indeed, given that $l=0$, for $\mu>0$ we have $\operatorname{Pr}[g \mid F, S, \bar{C}]=0$ according to Eq.(4). In turn, the judge's rationality condition (condition 5) implies that $\operatorname{Pr}[I \mid S, \bar{C}]=0$. But the $b$-worker sues the firm (plays $S$ ) if:

$$
E\left[U^{w} \mid S, F, b\right] \geq 0 \Leftrightarrow y \geq k X_{1}=k \frac{\operatorname{Pr}[C]+(1-\operatorname{Pr}[C])(1-\operatorname{Pr}[I \mid S, \bar{C}])}{(1-\operatorname{Pr}[C]) \operatorname{Pr}[I \mid S, \bar{C}]}
$$

yet here $\lim _{\operatorname{Pr}[I \mid S, \bar{C}] \rightarrow 0} X_{1}=\infty$, so $y \geq k X_{1}$ is impossible.

Let us consider the opposite case, $\mu=0$. If no worker sues the firm $(P[S] \rightarrow \infty)$, judges can detect without error the type of one worker who would choose to sue:

$$
\operatorname{Pr}[C]=\min \left\{\frac{\theta}{P[S]}, 1\right\}=\min \left\{\frac{\theta}{\alpha l m+(1-\alpha) \lambda \mu}, 1\right\}=1
$$

Hence,

$$
\lim _{\operatorname{Pr}[C] \rightarrow 1} X_{1}=\lim _{\operatorname{Pr}[C] \rightarrow 1} \frac{\operatorname{Pr}[C]+(1-\operatorname{Pr}[C])(1-\operatorname{Pr}[I \mid S, \bar{C}])}{(1-\operatorname{Pr}[C]) \operatorname{Pr}[I \mid S, \bar{C}]}=\infty
$$

so condition $y<k X_{1}$ is always fulfilled. In particular, $X_{2}=\frac{(1-\operatorname{Pr}[C])(1-\operatorname{Pr}[I \mid S, \bar{C}])}{\operatorname{Pr}[C]+(1-\operatorname{Pr}[C]) \operatorname{Pr}[I \mid S, C]}$ so, in equilibrium, we have:

$$
X_{2}=0
$$

Given that $k X_{2}<y$, it turns out that a $g$-type worker would systematically sue the firm if he is fired for a personal motive (i.e., $m=1$ ). 
We turn now to condition (a). According to definition (18), we have:

$$
Y_{1}=\frac{n-\mu(1-\operatorname{Pr}[C]) \operatorname{Pr}[I \mid S, \bar{C}]}{\mu(1-\operatorname{Pr}[C]) \operatorname{Pr}[I \mid S, \bar{C}]}
$$

with $\lim _{\operatorname{Pr}[I \mid S, \bar{C}] \rightarrow 0} Y_{1}=\infty$. Therefore $y<k Y_{1}, b$-type workers are always fired for personal motives (i.e., $\lambda=1$ ).

Then, we have:

$$
Y_{2}=\frac{n-m\{\operatorname{Pr}[C]+(1-\operatorname{Pr}[C]) \operatorname{Pr}[I \mid S, \bar{C}]\}}{m\{\operatorname{Pr}[C]+(1-\operatorname{Pr}[C]) \operatorname{Pr}[I \mid S, \bar{C}]\}}=\frac{n-m}{m}
$$

Condition $y<k Y_{2}$ where $g$ workers are also fired for personal motives would imply: $y<k Y_{2} \Leftrightarrow$ $y+k<N$. But the largest cost that the firm should pay if it is taken to courts $(y+k)$ cannot be smaller than $N$, if else the problem becomes trivial (no worker would be fired for economic motives).

So $Y_{2}<y<k Y_{1}$ and $k X_{2}<y<k X_{1}$ whatever the parameters of the problem: the separating equilibrium is always possible.

\subsection{The case $X_{1}<Y_{2}$. A pooling equilibrium: all workers fired for per- sonal motives, all sue the firm}

We study now the case where $X_{1}<Y_{2}$. Appendix 1 shows that the only feasible equilibrium in pure strategies can happen if $k X_{2}<k X_{1}<y<k Y_{2}<k Y_{1}$. If these conditions jointly hold, all workers are fired for personal motives and all sue the firm, what we refer to as a pooling equilibrium, to emphasize that judges cannot infer a worker's type from his judicial strategy. The intuition behind this situation is easy to grasp: if all workers are fired and all sue, judges are subject to a huge flow of cases (of mass one), and they will sit with the workers with a probability $\alpha<1$. But because judges can make errors, firms do fire good workers for a personal motive, and bad workers do sue the firm.

Formally, for $\lambda=1$ and $l=1$ the manager's strategy is $s^{f}(i)=F, \forall i \in\{b, g\}$ and, with $\mu=1$ and $m=1$, the workers' strategy becomes $s^{w}(i)=S, \forall i \in\{b, g\}$.

On the judge's side, for $P[S]=1$, the probability of control is:

$$
\operatorname{Pr}[C]=\min \left\{\frac{\theta}{P[S]}, 1\right\}=\theta
$$


Given that $\operatorname{Pr}[g \mid F, S, \bar{C}]=\frac{\alpha \operatorname{lm}(1-\operatorname{Pr}[C])}{[\alpha l m+(1-\alpha) \mu \lambda](1-\operatorname{Pr}[C])}=\frac{\alpha l m}{\alpha l m+(1-\alpha) \lambda \mu}=\alpha$, the judge's rationality condition (condition 5) becomes:

$$
\operatorname{Pr}[I \mid S, \bar{C}]=\alpha .
$$

Furthermore, as $X_{2}<X_{1}$ and $Y_{2}<Y_{1}$, a sufficient condition for this equilibrium to exist is:

$$
k X_{1}<y<k Y_{2} \text {. }
$$

with $X_{1} \equiv \frac{\operatorname{Pr}[C]+(1-\operatorname{Pr}[C])(1-\operatorname{Pr}[I \mid S, \bar{C}])}{(1-\operatorname{Pr}[C]) \operatorname{Pr}[I \mid S, \bar{C}]}=\frac{\theta+(1-\theta)(1-\alpha)}{\alpha(1-\theta)}$ and $Y_{2}=\frac{n-m\{\operatorname{Pr}[C]+(1-\operatorname{Pr}[C]) \operatorname{Pr}[I \mid S, \bar{C}]\}}{m\{\operatorname{Pr}[C]+(1-\operatorname{Pr}[C]) \operatorname{Pr}[I \mid S, \bar{C}]\}}$ $\frac{n-\{\theta+(1-\theta) \alpha\}}{\theta+(1-\theta) \alpha}$.

This condition can be fulfilled at least for some parameter values if the three conditions below hold together:

Condition (a):

$$
X_{1}<Y_{2} \Leftrightarrow \theta<\frac{\alpha(n-1)}{1+\alpha(n-1)} .
$$

As $n>1$, this condition can be fulfilled for a $\theta$ which is small enough. In particular, it is fulfilled for $\theta=0$

Condition (b) (both $b$-workers and $g$-workers sue):

$$
k X_{1}<y \Leftrightarrow \theta<\frac{\alpha(y+k)-k}{\alpha(y+k)} .
$$

This condition can be fulfilled for a small $\theta$ provided that $\alpha(y+k)-k>0 \Leftrightarrow \alpha>\left(\frac{k}{y+k}\right)$.

Condition (c) (both $b$-workers and $g$-workers are fired for personal motives):

$$
y<k Y_{2} \Leftrightarrow \theta<\frac{\tau-\alpha}{1-\alpha}
$$

where $\tau<1$ stands for $\frac{n k}{y+k}$. This condition can be fulfilled for a very small $\theta$ provided that $\alpha<\tau$.

Thus, in general, conditions (b) and (c) are jointly fulfilled if $\theta<\min \left\{\frac{\alpha(y+k)-k}{\alpha(y+k)}, \frac{\tau-\alpha}{1-\alpha}\right\}$. Therefore, a necessary condition for the pooling equilibrium to exist is $\min \left\{\frac{\alpha(y+k)-k}{\alpha(y+k)}, \frac{\tau-\alpha}{1-\alpha}\right\}>$ $0 .^{6}$

\footnotetext{
6 In turn, this condition imposes some restrictions on $\alpha$ with respect to the relative payoffs. We will comment more on these restrictions in the next sections which present the hybrid equilibria.
} 
As shown in Appendix 1, for $X_{1}<Y_{2}$ the game also presents two hybrid equilibria, defined as a situation where at least one player plays a mixed equilibrium strategy.

\subsection{Hybrid equilibrium A: all $b$ workers and some $g$ ones are fired for personal motives, they all sue}

For given parameter values, the model presents a hybrid equilibrium where not only all $b$-workers are fired for personal motives, but so are some $g$-workers; they all go to courts. With the former notation, in this equilibrium we have $\lambda=\mu=m=1$ and $l \in] 0,1[$. The firm's strategy becomes:

$$
s^{f}(i)= \begin{cases}F & \text { if } i=b \\ l F+(1-l) \bar{F} & \text { if } i=g\end{cases}
$$

and the workers' strategy is $s^{w}(i)=S, \forall i \in\{b, g\}$.

On the judge's side, the control probability can be written:

$$
\operatorname{Pr}[C]=\min \left\{\frac{\theta}{P[S]}, 1\right\}=\min \left\{\frac{\theta}{\alpha l+(1-\alpha)}, 1\right\}
$$

In order to focus on a non trivial case, we admit that $\operatorname{Pr}[C]=\frac{\theta}{\alpha l+(1-\alpha)}<1 \Leftrightarrow \theta<\alpha l+(1-\alpha)$.

Given that $\operatorname{Pr}[g \mid F, S, \bar{C}]=\frac{\alpha l}{\alpha l+(1-\alpha)}$, the judge's rationality condition (condition 5$)$ is:

$$
\operatorname{Pr}[I \mid S, \bar{C}]=\frac{\alpha l}{\alpha l+(1-\alpha)} .
$$

Let us study the equilibrium conditions.

a) All the fired workers sue the firm $(\mu=m=1)$ if $k X_{1}<y$. In turn, this requires that the number of judges is small enough:

$$
\begin{aligned}
\frac{\operatorname{Pr}[C]+(1-\operatorname{Pr}[C])(1-\operatorname{Pr}[I \mid S, \bar{C}])}{(1-\operatorname{Pr}[C]) \operatorname{Pr}[I \mid S, \bar{C}]} & <\frac{n-m\{\operatorname{Pr}[C]+(1-\operatorname{Pr}[C]) \operatorname{Pr}[I \mid S, \bar{C}]\}}{m\{\operatorname{Pr}[C]+(1-\operatorname{Pr}[C]) \operatorname{Pr}[I \mid S, \bar{C}]\}} \\
\Leftrightarrow \theta & <\frac{\alpha l(n-1)(1-\alpha+\alpha l)}{1-\alpha+n \alpha l} .
\end{aligned}
$$

We will show later that the condition is fulfilled for $\theta \rightarrow 0$.

b) The firm is indifferent between firing a $g$-type worker for economic or personal motive if $y=k Y_{2}$. We develop the indifference condition such as to set the emphasis on $l$, the frequency of 
workers fired for a personal motive:

$$
\begin{aligned}
y & =k Y_{2} \\
& \Leftrightarrow \quad y=k \frac{n-m\{\operatorname{Pr}[C]+(1-\operatorname{Pr}[C]) \operatorname{Pr}[I \mid S, \bar{C}]\}}{m\{\operatorname{Pr}[C]+(1-\operatorname{Pr}[C]) \operatorname{Pr}[I \mid S, \bar{C}]\}} \\
& \Leftrightarrow \quad(\alpha l)^{2}\left(1-\frac{N}{y+k}\right)+(\alpha l)(1-\alpha)\left(1-\frac{2 N}{y+k}\right)+\theta(1-\alpha)-\frac{N}{y+k}(1-\alpha)^{2}=0 .
\end{aligned}
$$

We have here a second degree equation in $l$, whose root in the interval $[0,1]$ is the equilibrium frequency of fired workers. As we have denoted $\frac{N}{y+k}$ by $\tau<1$, equation (39) can be written:

$$
(\alpha l)^{2}(1-\tau)+(1-\alpha)(1-2 \tau)(\alpha l)+\theta(1-\alpha)-\tau(1-\alpha)^{2}=0 .
$$

Its roots are:

$$
l_{1,2}=\frac{(1-\alpha)}{\alpha} \frac{(2 \tau-1) \pm \sqrt{1-4 \theta(1-\tau) /(1-\alpha)}}{2(1-\tau)} .
$$

We notice that for $\theta<\tau(1-\alpha)$, one root is negative and the other is positive: $l_{1} l_{2}=\frac{\theta(1-\alpha)-\tau(1-\alpha)^{2}}{\alpha^{2}(1-\tau)}<$ $0 .{ }^{7}$

As we focus on the case where $\theta$ is small enough, we can assume that this condition is fulfilled. Let $l^{+}$denote the positive solution, with:

$$
l^{+}=\frac{(1-\alpha)}{\alpha} \frac{(2 \tau-1)+\sqrt{1-4 \theta(1-\tau) /(1-\alpha)}}{2(1-\tau)} .
$$

We notice that $l^{+}$is a monotonic decreasing function in $\theta$, with $l^{+}<1$ if $\theta>\frac{\tau-\alpha}{1-\alpha}$ and $l^{+}>0$ if $\theta<\tau(1-\alpha)$. The hybrid equilibrium A exists if there is a non empty set for $\theta$ such that $\left.l^{+} \in\right] 0,1[$. This requires that $\frac{\tau-\alpha}{1-\alpha}<\tau(1-\alpha)$, or, in an equivalent way:

$$
\frac{\tau-\alpha}{1-\alpha}<\tau(1-\alpha) \Leftrightarrow \alpha>2-\frac{y+k}{N} .
$$

Ceteris paribus, chances to have this condition fulfilled increase if $\alpha$ is large. If $\alpha$ is too small, chances that the judge sits with the workers are small (they are proportional to the number of good workers that sue), so bad workers would not take their case to courts. They will do so only if there are relatively many good workers that sue, hence they can fond into a mass of good workers.

On the other hand, condition $\theta>\frac{\tau-\alpha}{1-\alpha} \Leftrightarrow l^{+}<1$ is the opposite of condition (34) for which the pooling equilibrium can exist. It turns out that the pooling and the hybrid equilibrium A

\footnotetext{
7 The condition $l_{1} l_{2}<0$ is a sufficient condition for the existence of the roots.
} 
mutually exclude. Hence, the hybrid equilibrim can exist for a small $\theta(\theta \rightarrow 0)$, only if $\alpha>\tau$, if else firms will fire all the $g$-workers because their chances to win in courts (when all workers sue) are weak.

Turning now to the properties of this equilibrium, we can show that the equilibrium value of $l^{+}$(the frequency of bad workers who sue) is an increasing function in $\tau=\frac{N}{y+k}$. Writing the differential of Eq. (40) with respect to $l$ and $\tau$ :

$$
2 l(\alpha)^{2}(1-\tau) d l-(\alpha l)^{2} d \tau-2(1-\alpha)(\alpha l) d \tau+\alpha(1-\alpha)(1-2 \tau) d l-(1-\alpha)^{2} d \tau=0,
$$

we get the derivative:

$$
\frac{d l}{d \tau}=\frac{[(1-\alpha)+\alpha l]^{2}}{2 l \alpha^{2}(1-\tau)+\alpha(1-\alpha)(1-2 \tau)} .
$$

The sign of the derivative $\frac{d l}{d \tau}$ is given by the sign of $2 l \alpha^{2}(1-\tau)+\alpha(1-\alpha)(1-2 \tau)$. It can be checked that for $l=l^{+}$this sign is positive.

Finally, we argued that the equilibrium value of $l^{+}$is a monotonic decreasing function in $\theta$. For $\theta=0$ we get the largest positive root $l_{\theta=0}^{+}=\frac{(1-\alpha)}{\alpha} \frac{\tau}{(1-\tau)}>0$.We can check that condition (38) holds for $\theta \rightarrow 0$.

\subsection{Hybrid equilibrium B. All workers are fired for personal motives, all $g$ workers and some $b$ workers sue}

The game presents a second hybrid equilibrium, where all workers are fired for personal motives, and where all $g$ workers and a fraction $\mu \in] 0,1[$ of the $b$ workers sue.

With $\lambda=1$,and $l=1$ the firm's strategy is $s^{f}(i)=F, \forall i \in\{b, g\}$. The $g$-workers always sue $(m=1)$ and so do some $b$-workers $(\mu \in] 0,1[)$. Hence workers' strategy can be written:

$$
s^{w}(i)=\left\{\begin{array}{ll}
\mu S+(1-\mu) \bar{S} & \text { if } i=b \\
S & \text { if } i=g
\end{array} .\right.
$$

Turning to the judge's behavior, the control probability is:

$$
\operatorname{Pr}[C]=\frac{\theta}{\alpha+(1-\alpha) \mu}<1 .
$$

The judge's rationality condition becomes:

$$
\operatorname{Pr}[I \mid S, \bar{C}]=\operatorname{Pr}[g \mid S, \bar{C}]=\frac{\alpha \ln (1-\operatorname{Pr}[C])}{[\alpha \ln +(1-\alpha) \lambda \mu](1-\operatorname{Pr}[C])}=\frac{\alpha}{\alpha+(1-\alpha) \mu} .
$$


There are two equilibrium conditions.

a) All workers are fired for personal motives if $y<k Y_{2}$, that is, if:

$$
\begin{aligned}
& y<k \frac{n-\{\operatorname{Pr}[C]+(1-\operatorname{Pr}[C]) \operatorname{Pr}[I \mid S, \bar{C}]\}}{\operatorname{Pr}[C]+(1-\operatorname{Pr}[C]) \operatorname{Pr}[I \mid S, \bar{C}]} \Leftrightarrow \theta<\frac{\tau[\alpha+(1-\alpha) \mu]^{2}-[\alpha+(1-\alpha) \mu] \alpha}{(1-\alpha) \mu} \\
& \theta<\frac{[\alpha+(1-\alpha) \mu][\alpha(\tau-1)+(1-\alpha) \tau \mu]}{(1-\alpha) \mu} .
\end{aligned}
$$

We will show later on that for $\theta \rightarrow 0$ this condition is fulfilled.

b) $b$-workers are indifferent between suing the firm or not if $y=k X_{1}$. We determine the value of $X_{1}$ in this special case:

$$
X_{1}=\frac{\operatorname{Pr}[C]+(1-\operatorname{Pr}[C])(1-\operatorname{Pr}[I \mid S, \bar{C}])}{(1-\operatorname{Pr}[C]) \operatorname{Pr}[I \mid S, \bar{C}]}=\frac{\alpha \theta+\mu(1-\alpha)[\alpha+(1-\alpha) \mu]}{\alpha[\alpha+(1-\alpha) \mu-\theta]}
$$

The indifference condition leads to a second degree equation in $\mu$ :

$$
(1-\alpha)^{2} k \mu^{2}-\alpha(y-k)(1-\alpha) \mu-\alpha[y \alpha-\theta(y+k)]=0 .
$$

Its roots are:

$$
\mu_{1,2}=\frac{\alpha(y-k) \pm \sqrt{\alpha^{2}(y+k)^{2}-4 \alpha k \theta(y+k)}}{2(1-\alpha) k} .
$$

There is one positive and one negative real root if $\theta<\frac{\alpha y}{y+k}$. In the following, we admit that $\theta$ is small enough to fulfill this condition and denote the positive solution by:

$$
\mu^{+}=\frac{\alpha(y-k)+\sqrt{\alpha^{2}(y+k)^{2}-4 \alpha k \theta(y+k)}}{2(1-\alpha) k} .
$$

The hybrid equilibrium exists for $\left.\mu^{+} \in\right] 0,1\left[\right.$. The first condition, $\mu^{+}>0$, is tantamount to $\theta<$ $\frac{\alpha y}{y+k}$. The second condition, $\mu^{+}<1$, requires that $\theta>\frac{\alpha(y+k)-k}{\alpha(y+k)}$. It turns out that this equilibrium exists if the set $\left[\frac{\alpha(y+k)-k}{\alpha(y+k)}, \frac{\alpha y}{y+k}\right]$ is not empty. This requires that:

$$
\frac{\alpha(y+k)-k}{\alpha(y+k)}<\frac{\alpha y}{y+k} \Leftrightarrow \alpha<\frac{k}{y} \text {. }
$$

Chances that this condition holds get better for a small $y$ : indeed, in this case the firm has all the incentives to fire all workers for a personal motive. All the $g$-workers sue, but if the frequency of good workers is low ( $\alpha$ is small), so are chances to win for both good and bad workers.

Remark that condition $\mu^{+}<1 \Leftrightarrow \theta>\frac{\alpha(y+k)-k}{\alpha(y+k)}$ is the opposite of condition (33), one of the existence conditions of the pooling equilibrium. Hence the pooling and the hybrid equilibrium 
B mutually exclude. Thus, for $\theta \rightarrow 0$, this hybrid equilibrium can exit only if $\alpha<\frac{k}{y+k}$, if else chances of the $b$-workers to win are high and they would all go to courts.

The differential of Eq. (50) with respect to $y$ and $\mu$ :

$$
2(1-\alpha)^{2} \mu k d \mu-\alpha(y-k)(1-\alpha) d \mu-\alpha(1-\alpha) \mu d y-\alpha(\alpha-\theta) d y=0
$$

leads to the derivative:

$$
\frac{d \mu}{d y}=\alpha \frac{\mu(1-\alpha)+(\alpha-\theta)}{2(1-\alpha)^{2} \mu k-\alpha(y-k)(1-\alpha)} .
$$

Since we are concerned with the case where $\theta<\frac{\alpha y}{y+k}$ (and $\frac{\alpha y}{y+k}<\alpha$ ), the sign of the derivative is the sign of $2(1-\alpha)^{2} \mu k-\alpha(y-k)(1-\alpha)$. It can be easily shown that for $\mu=\mu^{+}$the sign is positive.

The positive root $\mu^{+}$is a monotonic decreasing function in $\theta$. For $\theta=0$ we get its largest value, $\mu_{\theta=0}^{+}=\frac{y}{k} \frac{\alpha}{(1-\alpha)}$. It can be checked that for $\mu=\mu_{\theta=0}^{+}$condition (48) holds. ${ }^{8}$

\section{Conclusion}

The original contribution of this paper to existing EPL literature is to emphasize that firms' firing costs and workers' severance payments depend not only on variables controlled by the government, but also on the prevailing equilibrium. In particular, it was shown that when firms' hiring and firing policies are subject to legal control by external judges, the economy features a built-in propensity for multiple equilibria. Thus firing costs and workers' benefits can change dramatically should the equilibrium change.

In our basic framework, firms must layoff a given number of employees, given that, in a perfect information setup, only some of them would qualify for what labor judges acknowledge to be a valid personal motive. Such a motive involves some form of inadequacy of the worker with the firm's values. The model builds on the idea according to which, judges, like any human beings, can make errors when they have to process a large number of files. While the paper does not describes in a detailed way the judges' decision making process, the error probability was brought into the picture in an endogenous way.

\footnotetext{
${ }^{8}$ Hybrid equilibrium A can occur if $\alpha>2-(1 / \tau)$ (with $\left.\tau=N /(y+k)<1\right)$ while Hybrid equilibrium B requires that $\alpha<k / y$. Hence, if $k / y>2-(y+k) / N$, there are $\alpha$ values for which hybrid equilibria $\mathrm{A}$ and $\mathrm{B}$ do not mutually exclude.
} 
There is one separating equilibrium that can prevail whatever the parameters of the problem, where firms fire for personal motives only those workers who really qualify for such a motive, fired workers do not sue the firm, and judges can detect without error the type of the worker should a worker sue the firm. Good workers are fired for economic motives, and get the generous legal compensation they are entitled to. While in this world there is no excessive frustration - each employee gets a fair deal and firms behave according to the law - one may ask what judges are good for. Indeed, they may seem to have to much spare time since no worker takes to courts the firm's decision. However, this stressless environment is an indication that judges perform well their role of dissuading deviant behavior.

The game presents other equilibria, that may occur for a broad range of parameter value and which are all characterized by an overwhelming flow of cases in the justice's hands. The logic behind these more sophisticated situations is explicit: the fact that overworked judges can make errors creates the incentive for firms to abusively fire good workers for faked personal motives, and also for bad workers to abusively sue firms. The more of the latter go to courts, the higher their chances to win, and the higher the risk for a good worker to lose his case. In turn, this situation validates the decision of the firm to fire for personal motives the good workers. As expected, the proportion of good workers subject abusive dismissal is decreasing with the justice cost and the fine for firms that perpetrate such abuses.

Contemporary trends in some Continental European countries where job protection relies heavily on judges' control over the firing motives seem to indicate a shift of the balance from the separating to some form of socially dominated hybrid equilibrium. In particular in France, many observers point out that labor courts seems to be overcrowded and that firms tend to abusively fire people for personal motives. In order to oppose this inefficient outcome, one may consider several solutions. Trivial ones would be an increase in fines for abusive dismissal, or an increase in the overall effectiveness of the judicial system (for instance, by hiring more judges). A more challenging solution, advocated by the Economic Commission (2006; 2007), the OECD (2006) and several labor economists (Cahuc and Kramarz, 2004; Blanchard and Tirole, 2004), would be a de-judicialisation of the employer-employee relationship, with a replacement of the right to chal- 
lenge the dismissal motive in courts by a substantial severance indemnity, to be paid whatever the reason of the separation. Such a system, at work in several developed countries (Austria, United States), might jointly suppress huge justice costs and large personal costs for those good employee fired for undue motives, to the expense of those job-unfitted workers who are winning cases under the going system.

\section{A Appendices}

We know that $X_{1}>X_{2}$ and $Y_{1}>Y_{2}$. Two polar cases can be imagined:

- $Y_{2}>X_{1}$, i.e.: $Y_{1}>Y_{2}>X_{1}>X_{2}$ or

- $Y_{2}<X_{1}$

We firstly consider the pure strategy equilibria, then turn to mixed strategy ones.

\section{A.1 Pure strategy equilibria: the case $Y_{2}>X_{1}$}

- Case 1: $k X_{1}<k Y_{2}<k Y_{1}<y$, all workers sue, no one is fired. Since no one is fired, no one must sue. If someone is fired and sue, the control probability is equal to one. We can check that $\lim _{\operatorname{Pr}[c] \rightarrow 1} X_{1}=\infty$, hence the case $y>k X_{1}$ is impossible.

- Case 2: $k X_{1}<k Y_{2}<y<k Y_{1}$, all workers sue, only the bad workers are fired. Since only $b$ workers are fired, only $b$ workers sue. The probability that the judges sit with the worker is zero, hence $\lim _{\operatorname{Pr}[I \mid S, \bar{C}] \rightarrow 0} X_{1}=\infty$. The case $y>k X_{1}$ is impossible.

- Case 3: $k X_{2}<k X_{1}<y<k Y_{2}<k Y_{1}$, all workers are fired, they all sue. This is the "pooling equilibrium" analyzed in the core of the paper.

- Case 4: $k X_{2}<y<k X_{1}<k Y_{2}<k Y_{1}$, all workers are fired, only the $g$ type sue. If only $g$ workers sue, judges should sit with them systematically, $\operatorname{Pr}[I \mid S, \bar{C}]=1$. In this case, $Y_{2}=n-1$. But $y<k Y_{2} \Rightarrow y<k(n-1)$ or $y+k<N$ which is impossible (if else the dismissal for economic motives would never be an option). 
- Case 5: $y<k X_{2}<k X_{1}<k Y_{2}<k Y_{1}$, all workers are fired, no one is suing. Since no one is suing, if one good worker deviates, the control probability is equal to one, and judges must sit with him. Formally $X_{2}=0$ which goes again $y<k X_{2}$. This equilibrium is impossible.

\section{A.2 Pure strategy equilibria: the case $Y_{2}<X_{1}$}

\section{A.2.1 Sub-case: $y<k Y_{2}<k X_{1}$ : all workers are fired}

There are two possibilities:

- Case 1: $k X_{2}<y<k Y_{2}<k X_{1}$ all workers are fired $\left(y<k Y_{2}\right)$, but only good ones sue $\left(k X_{2}<y<k X_{1}\right)$. Then judges must sit with the workers $\operatorname{Pr}[I \mid S, \bar{C}]=1$.We check that $Y_{2}=n-1$ and $y<k Y_{2} \Rightarrow y+k<N$, which is impossible.

- Case 2: All workers are fired $\left(y<k Y_{2}\right)$ and no one is suing $\left(y<k X_{2}<k X_{1}\right)$. With a unit control probability, good workers must sue, so this equilibrium is impossible.

\section{A.2.2 Sub-case: $k Y_{2}<k X_{1}<y:$ all the fired workers sue}

- Case 3: $k Y_{2}<y<k Y_{1}$, only bad workers are fired. In this case, the probability that the judge sits with the worker is zero, so no bad worker has an incentive to sue. This refutes the assumption that all workers sue. The equilibrium is impossible.

- Case 4: $k Y_{2}<k Y_{1}<y$, no one is fired. The control probability is equal to one. So $\lim _{\operatorname{Pr}[C] \rightarrow 1} X_{1}=\infty$ thus $k X_{1}<y$ is impossible

\section{A.2.3 Sub-case: $k Y_{2}<y<k X_{1}$}

- Case 5: $k Y_{2}<k Y_{1}<y$ no one is fired. Then the control probability is equal to one. We have $\lim _{\operatorname{Pr}[C] \rightarrow 1} Y_{1}=\infty$ so $k Y_{1}<y$ is impossible.

- Case 6: $k Y_{2}<y<k Y_{1}$ only bad workers are fired and $y<k X_{2}$ no worker sues. then the control probability is equal to one and $X_{2}=0$.We must have $y>k X_{2}$ which goes against the initial assumption.

- Case 7: $k Y_{2}<y<k Y_{1}$ only bad workers are fired and $k X_{2}<y<k X_{1}$ only good workers would sue (if fired), while fired b workers do not sue. This is the "separating equilibrium" 
analyzed in the core of the paper.

\section{A.3 Hybrid equilibria: the case $Y_{2}<X_{1}$}

It can be shown that in this case, hybrid equilibria either do not exist or require very restrictive conditions.

\section{A.3.1 Hybrid equilibrium 1: $k Y_{2}=y<k X_{1}$ all bad and some good workers are fired, only good ones sue}

If only good ones sue, the probability that the judge sits with workers is equal to one. We can check that $Y_{2}=n-1$. Then condition $k Y_{2}=y$ requires $N=y+k:$ the firm is indifferent between firing a good worker for economic motives (and paying $N$ ) or firing him for personal motives and having to pay after the trial $y+N$ with certitude. On the other hand, b workers wont sue only if the control probability is strong enough. Since $X_{1}=\frac{\operatorname{Pr}[C]}{1-\operatorname{Pr}[C]}$, this very special case requires that $N=y+k$ and $y<k \frac{\operatorname{Pr}[C]}{1-\operatorname{Pr}[C]}$.

\section{A.3.2 Hybrid equilibrium 2: $k Y_{2}<y=k X_{1}$ only the b workers are fired, all the} g-type and a few b workers sue

Since only workers are fired, the judge neve sits with the workers. We have $\lim _{\operatorname{Pr}[I \mid S, \bar{C}] \rightarrow 0} X_{1} \rightarrow \infty$ so condition $y=k X_{1}$ is impossible.

\section{A.3.3 Hybrid equilibria when $X_{1}<Y_{2}$}

Two equilibria, which occur for $y=k X_{1}$ and $y=k Y_{2}$, are possible. We study them in the core of the paper.

\section{B References}

Amira, Selma and Gilbert De Stefano, 2005, Contrats à durée déterminée, intérim, apprentissage, contrats aidés, DARES, Premières Syntèses Informations, Avril, 14, 2.

Bentolila S and Bertola G, 1990, Firing costs and labor demand: How bad is Eurosclerosis, Review of Economic Studies, 57, pp.381-402.

Bertola, G., 1990, Job security, employment and wages, European Economic Review, 34, pp. 851886. 
Blanchard, Olivier and Augustin Landier, 2002, The perverse effects of partial labour market reform: Fixed-term contracts in France, Economic Journal, 112, pp. F214-F244.

Blanchard, Olivier and Jean Tirole, 2004, Redesigning the employment protection system, De Economist, 152, 1, pp. 1-20.

Blanchard, Olivier and Justin Wolfers, 2000, The role of shocks and institutions in the rise of European unemployment: The aggregate evidence; Economic Journal, v. 110, iss. 462, pp. C1-33 Cahuc, Pierre and Winfried Koeniger, 2007, Feature: Employment protection legislation, Economic Journal, 117, pp. F185-F188.

Cahuc, Pierre and Stéphane Carcillo, 2006, Que peut-on attendre des contrats nouvelle embauche et première embauche ?, Revue Francaise d'Economie, 21, pp. 37-86.

Cahuc, Pierre and Francis Kramarz, 2004, De la précarité, à la mobilité: vers une sécurité sociale professionnelle, Rapport au Ministre d'Etat, Ministre de l'Economie, des Finances et de l'Industrie et au Ministre de l'Emploi, du Travail et de la Cohésion Sociale, www.ladocumentationfrancaise.fr/ rapports-publics/ 054000092/index.shtml.

Cahuc, Pierre and André Zylberberg, 2004, Labor Economics, MIT Press, Cambridge, MA.

Cahuc, Pierre and Fabien Postel-Vinay, 2002, Temporary jobs, employment protection and labor market perfomance, Labor Economics, 9, 1, pp. 63-91.

European Commission, 2006, Employment in Europe Report, European Comission, Bruxelles. European Commission, 2007, Towards common principles of flexicurity: More and better jobs through flexibility and security, COM 2007 359, Communication of the EC to the European Parliament, Luxemburg, Publication Office.

Ichino, Andrea, Michele Polo, Enrico Rettore, 2003, Are judges biased by labor market conditions?, European Economic Review, 47, pp. 913-944.

Junod, Bérengère, Christine Lagrenne, Claude Minni, Laure Berne, 2006, Le contrat nouvelles embauches, DARES, Premières Synthèses Informations, Juin, 25, 4.

Lagrenne, Christine and Marine Le Roux, Les licenciements en 2003, DARES, Premières Synthèses Informations, Mars, 11, 1.

Levy, Gilat, 2005, Careerist judges and the appeal process, Rand Journal of Economics, 36, 2, pp. 
$275-297$.

L'Haridon Olivier and Franck Malherbet, 2006, Employment protection reform in search economies, IZA Discussion Paper 2304.

Ljungqvist, L., 2002, How do layoff costs affect employment?, Economic Journal, 112, pp. 829-853. Munoz Perez, Brigitte and Evelyne Severin, 2005, Le droit de travail en perspective contentieuse 1993-2004, Ministère de la Justice, DACS 2005-2, Novembre.

Phleps, Edmund S. and Gylfy Zoega, 2001, Structural booms, Economic Policy, 16, 32, pp. 83-126.

Pigoni, Maria-Theresa and Patrick Zouary, 2003, Les nouveaux usages du licenciement pour motif personnel, DARES, Premières Synthèses Informations, Juillet, 28, 2.

Posner, Richard A., 1993, What do judges and justices maximize?, (The same thing everybody else does), Supreme Court Economic Review, 3, pp. 1-40.

Taha, Ahmed E., 2004, Publish or Paris? Evidence of how judges allocate their time, American Law and Economics Review, 6, 1, pp. 1-27.

OECD, 2006, General policies to improve employment opportunities for all, Chapter 3, OECD Employment Outlook, OECD, Paris, pp. 95-99. 